\title{
Climate policy and equity principles \\ Fair burden sharing in a dynamic world
}

\section{Journal Article}

Author(s):

Bretschger, Lucas

Publication date:

2013-10-01

Permanent link:

https://doi.org/10.3929/ethz-b-000071274

Rights / license:

In Copyright - Non-Commercial Use Permitted

Originally published in:

Environment and Development Economics 18(5), https://doi.org/10.1017/S1355770X13000284 


\title{
Climate policy and equity principles: fair burden sharing in a dynamic world
}

\author{
LUCAS BRETSCHGER \\ Centre of Economic Research at ETH Zurich (CER-ETH), ZUE F7, \\ $\mathrm{CH}-8092$ Zurich, Switzerland. \\ Tel: +414463221 92. Fax: +41446321362. \\ Email: lbretschger@ethz.ch
}

Submitted 25 May 2012; revised 15 March 2013; accepted 24 March 2013; first published online 29 May 2013

\begin{abstract}
The paper argues that negotiation costs can prevent the international community from finding a new international climate agreement. To define a feasible way of facilitating the negotiation process, I analyze basic equity principles and their relationship to climate policy and economic development. Based on the most relevant principles, I propose a general synthetic rule for burden sharing in international climate policy. The rule avoids complexity and comprises both egalitarian and cost-sharing aspects, which appears to be crucial for achieving a climate agreement. Carbon budgets for the different countries are calculated under different parameter assumptions.
\end{abstract}

\section{Introduction}

The task of reaching a new international climate agreement is difficult due to specific conditions affecting costs and benefits of the different countries. First, perceived costs of climate mitigation are substantial, because fossil fuels are still widely used in most economies. ${ }^{1}$ This stands in sharp contrast to the successful Montreal Protocol on the ozone layer, where the costs of protection were small (and the benefits were large). Second, the negative effects of climate change are unevenly distributed across the different countries. Specifically, many low-developed countries are most vulnerable to climate change due to their geographical location and dependence on agriculture (see World Bank, 2010). Also, adaptation to changing climate

1 A survey of the costs according to 10 of the world's leading integrated assessment models is given in Clarke et al. (2009); for the costs in a fully dynamic model, see Bretschger et al. (2011).

The author thanks Max Meulemann, Stefan Ruchti, Pierre Lasserre, Julien Daubanes, Martin Stadelmann, Philippe Thalmann and two anonymous referees for valuable comments and Laura Ochoa for providing technical assistance with the data. 
conditions is relatively easier for high-developed economies because capital and knowledge are more abundant. Accordingly, not all the countries are evenly concerned about climate change when acting in their own selfinterest. $^{2}$ Third, as a matter of fact, the offer of side payments and the credibility of threats to restrict trade with non-signatory parties is more complex in the climate context than for other international frameworks.

In the literature on international environmental treaties, the search for self-enforcing agreements has dominated (see Bosello et al., 2003; Barrett, 2005). ${ }^{3}$ There has been much consideration on how to build coalitions and how to attract countries to join. Hence, it has been assumed that countries can freely choose whether to be a signatory or a non-signatory. Moreover, the costs of negotiating an international contract are usually disregarded. However, following the Durban platform in 2011, the character of the international decision process for climate policy has changed substantially. On the one hand, the international agreement has to be negotiated within a very limited time period, so that the efficiency of negotiations and the reduction of complexity become key. On the other hand, according to the Durban climate agreement, the climate coalition is fixed, encompassing the whole world community (see UNFCCC, 2011). ${ }^{4}$ If under the new regime some countries choose to be a non-signatory the treaty fails. Note that, given the confirmed target of a maximum warming of $2^{\circ} \mathrm{C}$, the total budget for greenhouse gases should be determined by scientific results, so that the new treaty will be primarily about the international distribution of the burden of mitigation policies. ${ }^{5}$

The complexity of the negotiation issues, the asymmetric interest of countries, the limited time available, and the necessity to have all countries on board give rise to the concern that an agreement will not be possible because an acceptable proposition might not be finalized within the

${ }^{2}$ It has even been argued that transfers from the North to the South are more effective to help the South than climate mitigation (see Schelling, 1995); however, Bretschger and Suphaphiphat (2012) derive in a dynamic model that climate mitigation is more efficient for both North and South.

3 Specifically, it is explained that a 'self-enforcing agreement is credible in the sense that, given the participation decisions of others and the requirements of the treaty, no signatory can gain by withdrawing and no non-signatory can gain by acceding; signatories cannot gain collectively by changing their aggregate abatement; and no non-signatory can gain by changing its decision to abate' (Barrett, 2005: 1468).

${ }^{4}$ Decision 1/CP.17 on the Durban Platform for Enhanced Action reads: 'The Conference of the Parties ... decides to launch a process to develop a protocol, another legal instrument or an agreed outcome with legal force under the Convention applicable to all Parties ...; decides that the Ad Hoc Working Group on the Durban Platform for Enhanced Action shall complete its work as early as possible but no later than 2015 in order to adopt this protocol, another legal instrument or an agreed outcome with legal force at the twenty-first session of the Conference of the Parties and for it to come into effect and be implemented from 2020' (see UNFCCC, 2011).

${ }^{5}$ Feedback effects from the costs of climate policies on the chosen policy target are discussed in Tavoni et al. (2012). 
available time period. Hence, the current challenge is to propose a distribution of a given greenhouse gas budget across all the nations, which has the potential to be generally acceptable. It is important that such a proposal does not involve too high a negotiation cost, because this might prevent a deal to be agreed on within the remaining time period.

To provide useful guidelines for a feasible climate negotiation process, equity principles appear to be very relevant. ${ }^{6}$ These principles are likely to work as focal points during negotiations, which decrease negotiation costs substantially and may also be suitable for raising political acceptance (see Lange et al., 2007). ${ }^{7}$ I argue that the main reason to concentrate on focal points in international climate policy is negotiation costs. So far, there is not a generally agreed procedure or concept of how to use equity principles in climate policy. What is needed is a plausible mechanism to transform abstract principles into a form which is ready to be used in international climate negotiations. This is where the present paper aims to make a contribution. This paper proposes a concrete solution for international burden sharing, which includes egalitarian aspects but does not impose equal sharing of resources as a first principle. Moreover, the proposed fairness rule also comprises cost-sharing aspects, which appear to be crucial for political acceptance, without declaring political constraints to be on the level of the principles.

The provided solution is based on a broad set of principles but becomes very simple in the end; it allows the debate to eventually concentrate on a single variable and two parameters. The achieved reduction of complexity is aimed at supporting the political decision-making process. The paper starts with an approach modelling the costs of climate negotiations in order to motivate the need for generally acceptable negotiation items. It then provides a brief evaluation of the most relevant equity principles. As a novel aspect, it stresses the fact that development is a dynamic process, which cannot be evaluated in a purely static framework. I argue that changes in technology and carbon efficiency must have an impact on the general policy assessment. Starting from broadly acceptable first principles, the paper derives a simple equation to calculate individual and country emission budgets. By a variation of the remaining parameters, different solutions can be evaluated. For illustrative purposes and possible practical use, calculations on the country levels are given in the final part.

The contribution is related to Lange et al. (2007) putting forward the importance of equity principles in climate policy and Mattoo and Subramanian (2010) who present theory and practice of climate policy burden sharing, mainly focusing on ability to pay and efficiency principles. Rose et al. (1998), Konow (2003) and Grasso (2007) provide useful

6 The 1987 Montreal Protocol on the ozone layer is often seen as a successful implementation of equity principles in an international environmental issue, but it is obvious that the costs and benefits have also been more favorable for reaching an agreement.

${ }^{7}$ It can also be argued that international negotiators have to consider the fairness preferences of their voters at home, but this will not be a focus of this paper. 
overviews on general equity principles; Cazorla and Toman (2000), Metz (2000), Grasso (2007), Page (2008) and Johansson-Stenman and Konow (2010) apply the principles to climate and environmental economics. Contributions stressing egalitarian principles are BASIC (2011) and Bode (2004). Other studies are mainly concerned with political constraints caused by adaptation policies and a lack of compliance and motivation; see Bosetti and Frankel (2009), McKibbin et al. (2010) and Gersbach and Winkler (2011), who present a broad calculation of the economic efforts required to achieve specific climate commitments. Blanford et al. (2008) show the importance of newly emerging economies, Bretschger and Valente (2011) derive the dynamic consequences of climate change, while Lange et al. (2010) remind us that in the negotiations, equity principles can also be used for selfish reasons. Finally, the model is linked to international negotiation theory (see Odell, 2006), where primarily strategies and specific negotiations skills are analyzed.

The remainder of the paper is organized as follows. Section 2 presents the social optimum when negotiation costs are non-negligible and based on a structured approach. Section 3 discusses the most relevant equity principles. In section $4 \mathrm{I}$ apply the principles to a climate policy proposal. Section 5 presents the country allocation results of the proposal. Section 6 concludes.

\section{Social optimum}

\subsection{Two-step procedure}

To achieve a (world) social optimum with carbon emissions, ${ }^{8}$ one has to consider two distinct maximization problems. The first is to determine optimum carbon abatement applying standard utilitarian principles. Efficiency is achieved by equalizing marginal cost and marginal benefits of abatement. The $2^{\circ} \mathrm{C}$ target of climate policy can be interpreted as a (broadly accepted) solution to this maximization problem. Based on the temperature target, science results have to determine the associated world carbon budget available in the future; see Meinshausen et al. (2009) for a calculation.

The second maximization problem consists in finding an agreeable treaty, realizing the potential net benefit of climate policies. Such an agreement is by no means automatically reached, even when the aggregate benefit is very large. Quite to the contrary, when assessing the previous conferences of the parties of the UNFCCC, negotiation costs have even proved to be enormous. A binding constraint is the limited time available for further negotiations. Hence, the second optimization problem is to obtain a generally acceptable climate deal, given the heterogenous interests of countries and the transaction costs of climate negotiations. The present paper takes the target world carbon budget as given and presents conditions under which a policy to achieve such a budget appear to be more easily acceptable by all the countries.

8 Throughout the paper, I use the term 'carbon' as a short expression for all the greenhouse gases. 
Formally, I study the process of finding an allocation of emission budgets $Z_{j}$ for countries $j=1,2, \ldots, N$, i.e., a series

$$
Z_{1}, Z_{2}, Z_{3}, \ldots Z_{N}
$$

In order to be a part of the set of feasible solutions, an allocation (1) has to obey several restrictions. Denoting world target carbon budget (which is compatible with the $2{ }^{\circ} \mathrm{C}$ target) by $\bar{Z}$, net benefits of an international climate agreement by $B$, and negotiation costs by $Q$, the restrictions read

$$
\begin{gathered}
\sum_{j=1}^{N} Z_{j} \leq \bar{Z} \\
B-Q>0 \\
B_{j}-Q_{j}>0, \forall j .
\end{gathered}
$$

While (2) is the world emission quantity constraint, (3) and (4) express that net benefits must exceed costs of negotiation both at the global and the country level. As I did not spell out preferences, net benefits in (4) may also include altruism towards low-developed countries ${ }^{9}$ and future generations; (4) corresponds to the assumption of 'international paretianism' of Posner and Weisbach (2012), but additionally includes negotiation costs. In the following I focus on condition (3) which, with given $B$, can only be met when $Q$ does not grow too large. Accordingly, the next section proposes a theory of negotiation costs identifying possible ways to reduce $Q$ so that (3) can be satisfied with given $B$. The following sections will deal with proposals likely to satisfy (3) and (4).

To study the issue in a systematic way, I need to make assumptions about the mechanics of the negotiation process. Notably, I have to specify negotiation technology and associated cost, which I present as a novel approach in the following subsection.

\subsection{Negotiation costs}

I argue that negotiation costs $Q$ are transaction costs and assume them to depend on the number of negotiating parties, the number and complexity of the negotiation items, the heterogeneity of interests between the parties, and the negotiation setting which determines how parties interact during negotiations. Often-used settings at international climate negotiations are plenary sessions, specialized sessions, country group meetings and bilateral talks. Experience of the climate negotiations shows that many decisions taken in specialized working groups or plenary sessions are solidly prepared in bilateral talks. Accordingly, the following approach to modeling negotiation costs uses the costs of bilateral talks as an element.

I first look at an extreme case, i.e., the maximum negotiation cost to obtain an agreement, and then discuss various ways to reduce the costs. If negotiations of a specific item like abatement targets require going through

9 This option is further explored in Anthoff and Tol (2010). 
all possible bilateral meetings with $N$ different parties, a total of $\left(N^{2}-N\right) / 2$ meetings are necessary, which shows the disproportional impact of the number of parties. Of course, a realistic setting helps to omit part of these meetings; I will discuss below which items are most likely to be successful in this respect. To obtain costs, the number of meetings has to be multiplied by average meeting costs, which depend positively on the number and the complexity of the negotiation items and the heterogeneity of parties' interests.

Theory has to focus on the fact that it usually takes several negotiation rounds before convergence between the involved parties is obtained. I label the different negotiation rounds by $t=1,2,3, \ldots$ and express negotiation costs in $t$ by $M(t)=\bar{M} \cdot V(t)$ where $\bar{M}$ is a negotiation-specific constant and $V$ a convergence factor, which increases between the rounds but converges to a steady state; an agreement requires $V(t+1)=V(t) .{ }^{10}$ Typically, a climate policy negotiation document includes different subitems which are sequentially agreed on by the parties. The dynamic process of $V$ depends on the speed by which parties are able to agree on these sub-items. Formally, I assume that $V$ evolves according to

$$
V(t+1)=(1-\phi) V(t)+\chi[V(t)]^{\xi}
$$

where $0<\phi, \xi, \chi<1$. Expression (5) allows discussion of the different dynamic elements of negotiation costs. The 'completion' parameter $\phi$ denotes the share of negotiation sub-items which has been agreed on in the previous round. The 'step' rate $\chi$ determines the increase of $V$ between the negotiation rounds; if $\xi=1$ the growth rate of $V$ equals $\chi-\phi$, i.e., it diminishes fast with low $\chi$, meaning a fast decrease of negotiation complexity. As an example, negotiations concerning technical issues like carbon capture and sequestration may decrease rapidly in complexity once the technicalities are well understood. The marginal impact of $\chi[V(t)]^{\xi}$ on $V(t+1)$ decreases with rising $V$ which results in convergence. The convergence term $\xi$ is low when additional negotiation rounds, increasing $V$, allow for rapid convergence; when it is high, convergence is slow. An example with little convergence and hence high $\xi$ has been the negotiation on technology transfers under the Bali action plan where country positions remained controversial for several years. The growth rate of $V$ is given by $\chi[V(t)]^{\xi-1}-\phi$ so that $V$ converges to $V^{*}=(\chi / \phi)^{1 /(1-\xi)}$ and aggregate negotiation costs $Q$ for a specific negotiation item are given by

$$
Q=\frac{\bar{M}\left(N^{2}-N\right)}{2}\left(\frac{\chi}{\phi}\right)^{1 /(1-\xi)}
$$

It becomes clear from (6) that high specific cost $\bar{M}$, a high step rate $\chi$ and a large convergence parameter $\xi$ entail high negotiation cost $Q$, while a large completion share $\phi$ decreases cost.

${ }^{10}$ When being strict, I have to formally assume the convergence criterion reading $V(t+1)(1-\varepsilon)=V(t)$ where $0<\varepsilon<1$ which guarantees finite convergence. 
Expression (6) allows us to analyze different negotiation items like abatements targets or burden-sharing rules with respect to their impact on $Q$ in (6). The number of parties $N$ is given at the United Nations but the (quadratic) term in (6) is based on the assumed complete bilateralism. Any items reducing the number of necessary bilateral meetings thus decrease the impact of $N$ on cost $Q$. Specifically, if an item is largely acceptable, countries may decide to negotiate in groups (like the G77), which reduces the number of necessary talks substantially. We then have a theory on bilateral talks between groups. Besides the obvious effects of $\bar{M}, \chi$ and $\phi$, it is the convergence parameter $\xi$ which is of special interest, because it has a disproportional impact on $Q$. A very complex item can cause slow convergence, i.e., a large number of additional negotiation rounds. This happens with a value of $\xi$ close to unity, increasing total negotiation cost $Q$ to a very large amount.

\subsection{Negotiation items}

I now look at different possible negotiation items and burden-sharing proposals at international climate negotiations with regard to the crucial model parameters $N$ and $\xi$ in (6).

- A pledge and review procedure for country abatement targets reveals countries' willingness to participate but has produced very unequal results between the countries. It is unclear to many, specifically to the non-pledging countries, how the offers compare between the countries, especially in terms of economic costs of climate policies. Recent climate conferences have proved that countries do not assess that the process generates a fair burden sharing; it has not produced sufficient convergence so far, indicating high $\xi$. Hence, the procedure seems to imply unfavorable values for $N$ and $\xi$ and thus a high $Q$.

- A second strategy is to include all the aspects determining the consequences of the pledges, i.e., to negotiate about economic cost, trade positions, money transfers, technology development and more. This increases the number of items drastically, which is not a very promising approach to bring about more favorable values for $N$ and $\xi$.

- The third strategy is on a very different level, proposing equity principles for the allocation of the carbon budget to countries which are generally accepted and considered to be fair. According to (6), the lower the number and the complexity of the negotiations items, the lower the values of $N$ and $\xi$ become, which improves the prospects of finding an agreement. Consequently, the paper proposes a burdensharing rule based on a very low number of equity principles. This is according to the requirement for low values of $N$ and $\xi$, i.e., low negotiation cost.

There are more possible variants but the paper moves on to the next topics for the sake of brevity. To conclude, the aim should be to propose a solution for burden sharing which is broadly considered as fair, clear and simple. This appears most promising when restrictions (3) and (4) have to 
be satisfied. Equity principles are a natural point of departure for such a reasoning. That in the end each and every country is willing to agree to such a climate deal might also imply some punishment for non-signatory countries. Specifically, if the condition (4) cannot be fulfilled without sanctioning non-signatories, trade sanctions could be put forward as a possible compliance mechanism, like under the Montreal Protocol. Trade sanctions may have undesirable effects but be compatible with free trade agreements in the case of border adjustments with obligations to buy allowances. The paper does not elaborate on this point but concentrates on equity principles as a means to reduce negotiation costs $Q$ in the following.

\section{Equity principles}

In his original contribution, Schelling (1980) introduces focal points as solutions to a problem which are natural, special or relevant. He explains that focal points are highly useful in negotiations because they are part of everybody's general expectations and suitable to build trust among the negotiating partners. In this section, equity principles are introduced as possible focal points for climate negotiations. I argue that these principles are a major means to decrease negotiation complexity and, hence, negotiation cost. I discuss and evaluate those principles which appear to be especially relevant for climate policy and useful for the international climate negotiation process. The latter is closely related to simplicity and intuition but also to verification, which is not given when rules depend on results from (complex) numerical models (see, e.g., Anthoff and Tol, 2010). The discussion is focused on the requirements of current climate policy and thus is not exhaustive with regard to the principles discussed in the literature. The paper is on climate mitigation policies; adaptation is only mentioned on the side.

The Egalitarian Principle in the form of an equal right to atmospheric resources has recently attracted considerable interest (see Bode, 2004; BASIC, 2011). However, despite its attributes of simplicity and immediate intuition, it has major drawbacks. It is conceivable to argue that, if it were applied to the atmosphere, it should also be applied to the other natural (and possibly manmade) resources, which is not a generally accepted view. Markets and policies usually have different objectives; countries allocate their own resources in a different manner. Hence, what is not the standard principle on a national level can hardly be the main guideline on an international level. Even more important, an equal use of atmospheric resources does not consider the context of the use. Notably, with the increasing availability of carbon-efficient technologies, carbon emissions become less imminent for human wellbeing and economic development compared to earlier periods. The often referred to right to develop has thus to focus on those factors which are crucial for development; among these, carbon emissions are much less imminent than, for example, capital, education and knowledge investments (see Bretschger et al., 2011). In addition, technical progress makes resource use more productive over time, so that - under equity considerations - emissions have to be evaluated in the context of the technology level. Nevertheless, the Egalitarian Principle can be applied 
in the sense that the equity rules of burden sharing should be applied on a per capita level (but in an adjusted form). Hence, every individual is treated in the same way, but, and this is crucial, with consideration of the context of its actions. The principle should be interpreted to allow for an 'equitable access to sustainable development', 11 which crucially depends on the availability of technologies, and in particular on carbon-efficient technologies, but not on absolute emission levels.

The Ability to Pay Principle requires the future allocation of carbon emissions to be inversely related to the ability to pay for emission reduction. It is closely related to the countries' capacity to contribute to solving the climate problem. ${ }^{12}$ It involves a redistribution of income, which is an issue in any policy context. The specific problem to consider with climate policy is that incomes are in general positively correlated not only with past but also with current carbon emissions, so that the costs to reduce carbon emissions are also related to income. Therefore, the Ability to Pay Principle may stand in contrast to the Efficiency Principle, which requires maximizing total surplus or, more precisely, minimizing the costs of carbon policy (see Rose et al., 1998; Konow, 2003: 1205). But note that the distribution of the costs of a global policy is not exclusively an efficiency but also an equity concern. The efficiency view is concerned with total costs becoming minimal, while the equity view argues that these costs should be distributed in a fair way, which is the way it is used in this paper. Accordingly, I will use the term Cost Sharing Principle below. A strong focus on the distribution of cost is reflected in the often quoted Grandfathering Rules, allocating the emission rights in proportion to current pollution.

Fairness and efficiency are often considered to be at odds but an appropriate policy can alleviate the conflict; the result of the present paper may serve as an example. The Ability to Pay Principle is also related to the Polluter Pays Principle, which assigns the burden of the policy proportionately to actual pollution. Both rules appear to be especially well suited for climate adaptation policies, in particular when defining the payments for funds used for adaptation measures. The Need Principle requires distributive justice with the aim of satisfaction of the basic needs of all individuals, which may include the use of the atmosphere.

The Desert Principle identifies factors justifying higher individual claims, in general on economic income and wealth (see Konow, 2003: 1207). From the different factors discussed in literature it emerges that differences attributable to effort are generally considered to be fair. In the context of climate policy, efforts relate to all contributions, enabling a delinking of income and welfare from carbon use. It thus appears to be a desert when advancing the productivity of atmospheric resource use by developing

11 The term was officially used for an ad hoc working group under Long-term Cooperative Action 2012; in economics, the term sustainability is mostly interpreted as 'weak sustainability' which means that aggregate productive capacities have to be preserved for future generations.

12 Put differently, the principles says 'the more one can afford to contribute, the more one should,' which is how most countries organize the financing of public goods, e.g., by progressive income taxation. 
carbon-efficient technologies and letting the rest of the world benefit through international knowledge provision. Some benefits of technology improvements are internalized, but this is by far not a sufficient reward; otherwise the climate problem could easily be solved. Besides our focus on the general technology level, this is a second dynamic ingredient which appears to be crucial for economic development. Many climate studies do not especially consider economic dynamics, while the present paper argues that dynamics are crucial when analyzing the access to a development which both decreases carbon emissions and increases welfare. We disregard further principles mentioned in literature for the sake of clarity and brevity. Specifically, possible political constraints are not considered as first principles. Also, more complicated statements based on numerical simulation models are not included. Finally, all the countries (including the less-developed economies) are included in the analysis.

When applying these principles to international carbon policy, several side conditions have to be settled. First, especially with international trade, one has to determine whether producers or consumers are liable for the consequences of resource use. The standards of income accounting and international law suggest that producers are responsible, but economics shows that, also in this case, consumers carry (part of) the burden of climate policy through (higher) prices of (imported) goods. Another issue is whether we should apply the same principles for distributing the burden in mitigation and adaptation policies. The discussion suggests that with adaptation we should refer more to the ability to pay and the polluter pays approach but the present paper is concerned with mitigation policy. As regards timing, we consider the period starting with Historic Responsibility (where the period of 'excusable ignorance' stops) ${ }^{13}$ and ending in the middle of the 21st century, because climate sciences have calculated feasible world carbon budgets up to this point in time (see Meinshausen et al., 2009). I will calculate country carbon budgets and not time paths, because these can be better optimized on the country level. Also, in order to optimize costs, countries should be allowed to internationally trade their initial emission entitlements. Additional services in land use and forest management may be included in calculating the entitlements, but this is not a focus here. I argue that responsibility also includes sharing resources among a country's population so that we count population of a country at the beginning of the 'responsibility' period.

\section{Application to climate policy}

\subsection{Using the principles}

There are many equity principles and different ways to apply them in climate policy proposals. The purpose of this subsection is to select some of the most accepted principles according to the literature (see, e.g., Lange et al., 2007; Mattoo and Subramanian, 2010). In the next subsection I

13 The most obvious starting date is 1990 but the calculations of the paper can also be applied with a different year. 
will complement them with a dynamic perspective which is crucial for the long-run sustainability aspects. The main guideline of the following consideration is to find a combination of equity principles which yields a clear and simple allocation rule for international carbon budgets. This is done in order to find a solution to the problem of (too) high negotiation cost, as analyzed above. I take that by the agreement on the Durban platform all the countries are included in the analysis. In addition, by the Cancun agreements, I assume that the $2^{\circ} \mathrm{C}$ target is confirmed. One can then adopt from natural science results what the remaining world carbon budget will be. Naturally, my calculation method could also be used for alternative carbon budgets and/or temperature targets.

The Ability to Pay Principle is included to derive the budgets as a measure of purchasing power, mainly for carbon-efficient technologies. The Cost Sharing Principle is employed to reflect the distribution of abatement costs (not to guarantee an efficient policy, this is done by allowing for permit trade). The Desert Principle is used for the provision of carbon-saving technical progress. The Polluter Pays Principle is included in the sense that past emissions are deducted from the overall carbon budget, possibly with a discount, depending on the valuation of historic responsibility. In the long-run steady state, one can assume that every individual will obtain an equal share of atmospheric resources, but this has no impact on my derivation, because I look at the transition of the economy towards sustainable development.

\subsection{Economic dynamics}

An important but so far neglected issue for an equitable solution in climate policy is the impact of economic dynamics, in particular technological development. When applying equity principles to climate policies one should compare like with like. Specifically, carbon emissions should be evaluated with respect to the technical opportunities available at the time of emission.

Regarding carbon saving technologies, recent changes have indeed been remarkable. According to World Bank (2012) data, the average annual growth rate of world $\mathrm{CO}_{2}$ emission intensity (global $\mathrm{CO}_{2}$ emissions per constant \$ of world GDP) for the period 1980-2008 amounts to -1.42 per cent. This means that, on average, the necessity to emit a ton of $\mathrm{CO}_{2}$ to produce a unit of output decreases by more than 1 per cent each year, which is respectable given the long time horizon of climate policy. The average annual growth rate of world $\mathrm{CO}_{2}$ emission intensity per capita even amounts to -2.9 per cent. ${ }^{14}$ World emission intensity and the respective growth rates are depicted in figure 1. Relating this finding to a fair burden allocation suggests that later developing countries have the advantage to have access to technologies with higher carbon efficiency, due to the diffusion of these technologies on world markets.

14 This makes it clear that to motivate the use of fossil fuels in terms of the 'right to development' or the 'basic needs' as equity principles will lose its attractiveness in the future. 

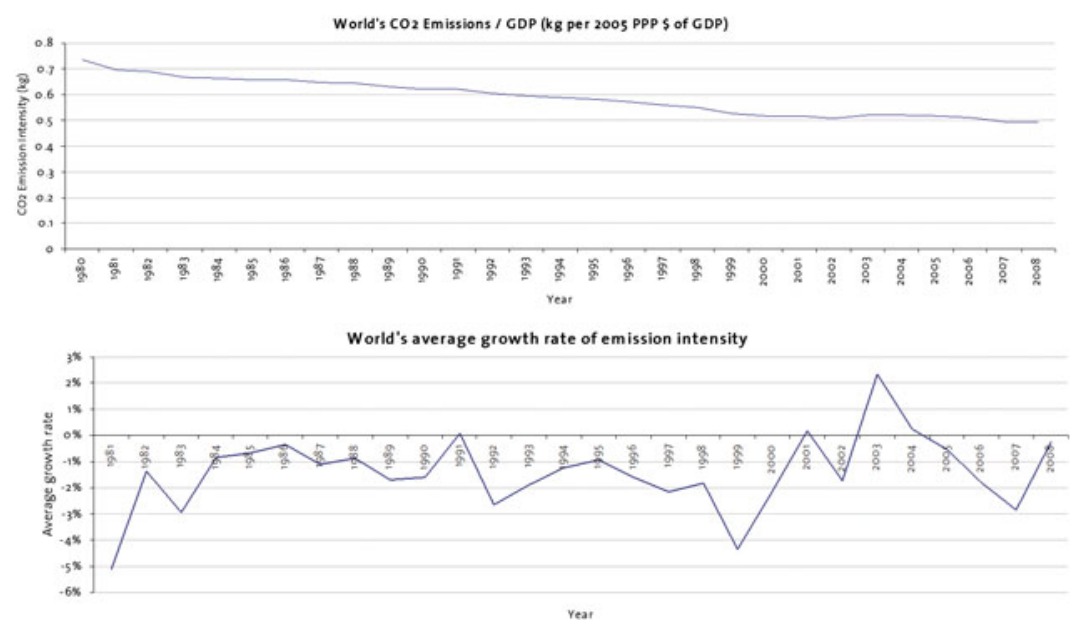

Figure 1. World emission intensity 1980-2008

Source: World Bank (2012).

\subsection{Fairness index}

The different principles are used to build a 'fairness' index $F$, which is a weighting index for fairness, used as the main ingredient to determine fair carbon budgets; a higher $F$ will yield a higher budget in the following. $F$ depends on four variables: the (inverse of the) Ability to Pay $A$, the abatement cost parameter $C$, the (individual or country) technology contribution $x$, and the general technology development $X$. All variables are measured for an individual $i$ at the beginning of the considered time period. An important methodological issue is how to combine these four factors mathematically, which ultimately determines their weight in the index. A broadly used technique is the weighted average, which relies on the (simple) arithmetic weighted average of the (normalized) variables. When the weights are the same for all the variables we get the so-called 'equally weighted averages'. The procedure is simple but the linearity implies constant substitutability among the different criteria, which is a strong assumption for international climate policy. It implies that a country can compensate (even extreme) deviations from the mean in one variable in exchange for other variables at a constant ratio. A more suitable procedure is to use the multiplicative form between the variables and define the weights in the exponents. In the present case, this leads to:

$$
F_{i}=A_{i}^{\alpha} \cdot C_{i}^{\beta} \cdot x_{i}^{\gamma} \cdot X_{i}^{\delta}
$$

where $0<\alpha, \beta, \gamma, \delta<1$ determine how the index $F$ increases when a variable on the right-hand side grows. Because the exponents are below unity, the index grows less than proportional with the single variables. For the following application, we measure each of the core variables by the best available indicator, knowing well that a certain degree of roughness is unavoidable with the procedure (in fact, with any procedure). In 
Table 1. Measuring the variables

\begin{tabular}{ccccc}
\hline & Ability to pay & Cost sharing & Techn. contrib. & Techn. develop. \\
\hline Variable & $A_{i}$ & $C_{i}$ & $x_{i}$ & $X_{i}$ \\
Measure & $L_{i}$ & $\frac{E_{i}}{L_{i}}$ & $\frac{Y_{i}}{E_{i}}$ & $\frac{E_{i}}{L_{i}}$ \\
\hline
\end{tabular}

concrete terms, we capture $A$ by the inverse of income $Y$ per capita $(L)$, the mitigation cost burden by emissions $E$ per capita $L$, the contribution to technology development by output $Y$ per emission $E$, and the context of general technology development by emissions $E$ per capita $L$. This last measure needs further explanation. To take initial emissions per capita as an indicator for future carbon technology development (which for obvious reasons is not directly measurable) relies on the assumption that the function of carbon efficiency development is monotonous. Put differently, the measure is meaningful when we assume that technical efficiency of carbon use is improving steadily, as has been the case in the past (see the previous subsection). Then, a person/country with high pollution in the beginning and a decreasing carbon profile is different from a person/country with low pollution in the beginning and rising emissions. With regard to carbon use, the first person/country has unambiguously less technical opportunities than the second. The measurement of the variables is represented in table 1.

Using this specification we get

$$
\begin{aligned}
F_{i} & =\left(\frac{L_{i}}{Y_{i}}\right)^{\alpha}\left(\frac{E_{i}}{L_{i}}\right)^{\beta+\delta}\left(\frac{Y_{i}}{E_{i}}\right)^{\gamma} \\
& =L_{i}{ }^{\alpha-\beta-\delta} E_{i}^{\beta+\delta-\gamma} Y_{i}^{\gamma-\alpha} .
\end{aligned}
$$

In a non-growing (static) economy, the technology development parameter is zero, i.e., $\delta=0$. Then, applying the equal weight method to the parameters in the exponent, we set $\alpha=\beta=\gamma$. Interestingly, this yields $F_{i}=1$, which is exactly the egalitarian solution with equal weights for every individual, like in BASIC (2011). But note that the result is not using equal carbon space as something like a first principle; the outcome emerges due to the exactly balancing effects of three (real) first principles; namely ability to pay, abatement costs and technology contribution.

However, I argue that the considered economies are inherently dynamic, mainly driven by technical progress. Hence, taking $\delta>0$ and applying the equal weight rule to all the four variables, we have $\alpha=\beta=\gamma=\delta$ in order to obtain

$$
F_{i}=\left(\frac{E_{i}}{L_{i}}\right)^{\alpha} .
$$

This expression has many interesting aspects. It reduces the highly complex problem of burden sharing in international climate policy to one single variable $\left(E_{i} / L_{i}\right)$ and a unique parameter $(\alpha$, with $\alpha=\beta=\gamma=\delta)$. It offers 
a close link to natural sciences and, moreover, an easy calculation method for the emission budgets. Importantly, with the link to (initial) emissions it opens the door to (possible) political acceptance, much like the grandfathering rules used with past carbon policy, without using political constraints as first principle. The derived relationship is nonlinear, so that the impact of emissions on the index fades with increasing emissions. Nonlinearity is even high, because, with the obvious restriction $\alpha+\beta+\gamma+\delta=1$, we have $\alpha=0.25$.

Following the discussion on negotiation cost, the positive attributes of the simple formula (9) are as follows: (i) it is ethically defensible, (ii) it is likely to cut negotiation cost enormously, and (iii) it has no negative impact on market efficiency when carbon trading is possible after the first allocation. Note that the simplicity of (9) is due to the used weights which are equal. If the assumption is disputed, an increase in negotiation costs is the inevitable consequence.

\subsection{Budget calculation}

Individual allocation

Each individual $i$ receives an emission budget $B_{i}$ according to the individual fairness index $F_{i}$ and the total amount of entitlements $Z$ available, according to

$$
B_{i}=\frac{F_{i}}{\sum_{i=1}^{L} F_{i}} \cdot Z
$$

\section{Country allocation}

Let us define the population share of country $j$ as $m_{j}(t)=L_{j}(t) / L(t)$ and use $N$ for the number of countries. Each country receives an emission budget $Z_{j}$ according to the weighting index $F_{j}$ (reflecting the fair index for country $j$ ), the country share $m_{j}$, and the total amount of entitlements $Z$ available in total, so that

$$
Z_{j}=\frac{m_{j} \cdot F_{j}}{\sum_{j=1}^{N} m_{j} \cdot F_{j}} \cdot Z
$$

\subsection{Historic responsibility}

So far we have not distinguished between different time periods. The whole period to consider starts with historic responsibility and is assumed to end in 2050, because current budget calculations provided by natural sciences end at that point in time. Because of natural decay of greenhouse gases and the absence of legal obligations in the past we might value past carbon use differently from future use. For practical reasons, we will distinguish between a first period, starting with the date of historic responsibility up to the point where the most recent statistics are available, and a second period, from that point in time until 2050. For the budget calculation, we assume the countries to receive entitlements according to the fairness index as derived above but now posit that actually used emissions in the first 
period may be discounted with a factor $0<\theta<1$. In the concrete calculations, we will compare carbon budgets for the responsibility values $\theta=1.0$; $0.8 ; 0.5$; and 0 .

\section{Country results}

\subsection{Assumptions}

To provide concrete information about the derived fairness equation, this section calculates country carbon budgets, using the fairness index $F$ and a specific set of assumptions. Of course, the general concept equally holds when different parameter specifications and time periods are more politically acceptable. The assumptions for the calculations here are:

- Start of (historic) responsibility: 1990

- First ('responsibility') period; 1990-2008 (1990 is the starting date of international climate policy; for 2008 the last international data on carbon use are available)

- Second ('carbon budget') period: 2008-2050 (feasible world carbon budgets were calculated up to 2050)

- Total carbon budget $Z$ for 1990-2050: (i) 'Variant 50 per cent', i.e., carbon emissions corresponding to a probability of 50 per cent of exceeding $2^{\circ} \mathrm{C}$, and (ii) 'Variant 33 per cent', i.e., the equivalent for a probability of 33 per cent, based on Meinshausen et al. (2009) who cover 2000-2050, plus carbon emissions 1990-2000, yielding 1,640 gigatons in total for 'Variant 50 per cent' and 1,360 gigatons for 'Variant 33 per cent'.

- Calculation of $E_{i} / L_{i}$ : per capita carbon emission data for 1990 as given by World Bank (2012).

- $\alpha=0.25(=\beta=\gamma=\delta)$

- Population size: 1990 values

- Valuation of emissions in the 'responsibility' period: scenarios for different levels of $\theta$ ranging from $\theta=1$ (full responsibility) to $\theta \rightarrow 0$ (no responsibility).

\subsection{Budgets}

Tables 2-4 show the carbon budgets for 2008-2050 for selected countries and four levels of historic responsibility, given by different values of $\theta$. The tables contain two sections, with the 'Variant 50 per cent' $(1,640$ gigatons in total) given on the left and the lower 'Variant 33 per cent' (1,360 gigatons) on the right. Table 2 contains the total budget, table 3 the budget per capita (using 2008 population values), and table 4 the average budget per capita per year.

By inspection of the tables it becomes clear that the shares (specifically the budgets per capita) are not very unequal between the different countries. Late-developing countries and high past polluters receive relatively lower budgets. Less-developed economies have the possibility to increase per capita emissions compared to current emissions, at least in a first time period. The common issue for higher developed countries is that they have to cut emissions compared to previous levels, although in a differentiated manner. 
Table 2. Total budget (period 2008-2050 in gigatons)

\begin{tabular}{|c|c|c|c|c|c|c|c|c|}
\hline \multirow{2}{*}{$\begin{array}{l}\text { Country } \\
\text { name }\end{array}$} & \multicolumn{4}{|c|}{$50 \%$ probability } & \multicolumn{4}{|c|}{$33 \%$ probability } \\
\hline & $\theta=1$ & $\theta=0.8$ & $\theta=0.5$ & $\theta \rightarrow 0$ & $\theta=1$ & $\theta=0.8$ & $\theta=0.5$ & $\theta \rightarrow 0$ \\
\hline China & 294.36 & 287.08 & 277.96 & 266.21 & 230.95 & 223.21 & 213.98 & 202.81 \\
\hline India & 195.84 & 185.50 & 172.55 & 155.86 & 158.71 & 147.71 & 134.61 & 118.74 \\
\hline $\begin{array}{l}\text { United } \\
\text { States }\end{array}$ & 26.20 & 43.12 & 64.31 & 91.62 & 4.38 & 22.38 & 43.82 & 69.80 \\
\hline Indonesia & 43.12 & 40.92 & 38.15 & 34.58 & 34.89 & 32.54 & 29.74 & 26.35 \\
\hline $\begin{array}{l}\text { Russian } \\
\text { Fed. }\end{array}$ & 32.33 & 36.07 & 40.74 & 46.77 & 21.19 & 25.17 & 29.90 & 35.63 \\
\hline Brazil & 36.76 & 35.14 & 33.11 & 30.50 & 29.49 & 27.77 & 25.72 & 23.24 \\
\hline Japan & 29.18 & 31.24 & 33.81 & 37.13 & 20.34 & 22.53 & 25.13 & 28.29 \\
\hline Mexico & 22.02 & 21.76 & 21.43 & 21.01 & 17.01 & 16.73 & 16.41 & 16.01 \\
\hline Germany & 17.88 & 19.63 & 21.82 & 24.64 & 12.01 & 13.87 & 16.09 & 18.77 \\
\hline Nigeria & 19.93 & 18.71 & 17.18 & 15.21 & 16.30 & 15.01 & 13.46 & 11.59 \\
\hline Bangladesh & 17.61 & 16.42 & 14.93 & 13.02 & 14.51 & 13.24 & 11.74 & 9.92 \\
\hline France & 14.88 & 15.16 & 15.50 & 15.95 & 11.08 & 11.37 & 11.73 & 12.15 \\
\hline $\begin{array}{l}\text { United } \\
\text { Kingdom }\end{array}$ & 13.51 & 14.47 & 15.67 & 17.22 & 9.40 & 10.43 & 11.65 & 13.12 \\
\hline Thailand & 14.81 & 14.45 & 14.00 & 13.41 & 11.61 & 11.23 & 10.77 & 10.22 \\
\hline Turkey & 14.07 & 13.76 & 13.38 & 12.87 & 11.01 & 10.68 & 10.28 & 9.81 \\
\hline Ukraine & 12.93 & 13.42 & 14.03 & 14.83 & 9.40 & 9.92 & 10.54 & 11.29 \\
\hline Vietnam & 14.14 & 13.31 & 12.27 & 10.93 & 11.53 & 10.65 & 9.60 & 8.33 \\
\hline Korea, Rep. & 10.22 & 10.88 & 11.72 & 12.80 & 7.17 & 7.88 & 8.72 & 9.75 \\
\hline Colombia & 8.03 & 7.66 & 7.19 & 6.58 & 6.46 & 6.06 & 5.59 & 5.01 \\
\hline Peru & 4.98 & 4.72 & 4.39 & 3.96 & 4.04 & 3.76 & 3.42 & 3.02 \\
\hline $\begin{array}{c}\text { Congo, } \\
\text { D.R. }\end{array}$ & 4.45 & 4.13 & 3.73 & 3.22 & 3.68 & 3.34 & 2.94 & 2.46 \\
\hline Kenya & 4.13 & 3.86 & 3.51 & 3.07 & 3.40 & 3.11 & 2.76 & 2.34 \\
\hline Australia & 2.21 & 3.22 & 4.49 & 6.12 & 0.75 & 1.83 & 3.11 & 4.66 \\
\hline Nepal & 2.68 & 2.50 & 2.26 & 1.96 & 2.22 & 2.02 & 1.78 & 1.49 \\
\hline $\begin{array}{l}\text { Cote } \\
\text { d'Ivoire }\end{array}$ & 2.42 & 2.27 & 2.07 & 1.83 & 1.99 & 1.82 & 1.63 & 1.35 \\
\hline Uganda & 2.28 & 2.12 & 1.92 & 1.66 & 1.88 & 1.71 & 1.51 & 1.26 \\
\hline Bolivia & 1.55 & 1.47 & 1.37 & 1.24 & 1.25 & 1.17 & 1.07 & 0.94 \\
\hline Cambodia & 1.54 & 1.44 & 1.30 & 1.14 & 1.27 & 1.16 & 1.03 & 0.86 \\
\hline Senegal & 1.42 & 1.33 & 1.22 & 1.08 & 1.17 & 1.07 & 0.96 & 0.82 \\
\hline Norway & 1.03 & 1.08 & 1.16 & 1.25 & 0.73 & 0.79 & 0.86 & 0.95 \\
\hline
\end{tabular}

As can be seen from the tables, historic responsibility matters especially for the United States, but is also an issue for other countries like Russia or Japan. The outcome suggests that historic responsibility is likely to be an important separate negotiation item. Otherwise, results are quite robust, also with respect to other model parameters.

Note that the values in table 4 are average emission values for the whole period and not final values for 2050 , which makes a big difference. The time profile is not predetermined by these calculations. 
Table 3. Budget per capita (period 2008-2050 in tons)

\begin{tabular}{|c|c|c|c|c|c|c|c|c|}
\hline \multirow{2}{*}{$\begin{array}{l}\text { Country } \\
\text { name }\end{array}$} & \multicolumn{4}{|c|}{$50 \%$ probability } & \multicolumn{4}{|c|}{$33 \%$ probability } \\
\hline & $\theta=1$ & $\theta=0.8$ & $\theta=0.5$ & $\theta \rightarrow 0$ & $\theta=1$ & $\theta=0.8$ & $\theta=0.5$ & $\theta \rightarrow 0$ \\
\hline China & 219.95 & 214.51 & 207.70 & 198.92 & 172.57 & 166.79 & 159.89 & 151.54 \\
\hline India & 167.25 & 158.42 & 147.36 & 133.11 & 135.54 & 126.15 & 114.96 & 101.41 \\
\hline $\begin{array}{l}\text { United } \\
\text { States }\end{array}$ & 84.78 & 139.51 & 208.07 & 296.46 & 14.17 & 72.42 & 141.80 & 225.85 \\
\hline Indonesia & 179.78 & 170.57 & 159.04 & 144.18 & 145.44 & 135.64 & 123.97 & 109.84 \\
\hline $\begin{array}{l}\text { Russian } \\
\text { Fed. }\end{array}$ & 228.09 & 254.43 & 287.42 & 329.96 & 149.51 & 177.53 & 210.92 & 251.37 \\
\hline Brazil & 188.54 & 180.24 & 169.85 & 156.45 & 151.28 & 142.45 & 131.93 & 119.19 \\
\hline Japan & 228.98 & 245.10 & 265.30 & 291.34 & 159.59 & 176.75 & 197.19 & 221.95 \\
\hline Mexico & 194.10 & 191.82 & 188.96 & 185.27 & 149.97 & 147.54 & 144.65 & 141.14 \\
\hline Germany & 218.84 & 240.23 & 267.02 & 301.55 & 147.02 & 169.78 & 196.89 & 229.73 \\
\hline Nigeria & 125.79 & 118.10 & 108.46 & 96.03 & 102.92 & 94.73 & 84.98 & 73.16 \\
\hline Bangladesh & 118.40 & 110.42 & 100.43 & 87.54 & 97.55 & 89.06 & 78.94 & 66.69 \\
\hline France & 229.33 & 233.62 & 238.99 & 245.92 & 170.76 & 175.33 & 180.76 & 187.35 \\
\hline $\begin{array}{l}\text { United } \\
\text { Kingdom }\end{array}$ & 217.06 & 232.52 & 251.88 & 276.84 & 151.13 & 167.58 & 187.17 & 210.90 \\
\hline Thailand & 214.20 & 209.00 & 202.48 & 194.07 & 167.98 & 162.44 & 155.84 & 147.85 \\
\hline Turkey & 193.46 & 189.19 & 183.85 & 176.96 & 151.31 & 146.77 & 141.37 & 134.82 \\
\hline Ukraine & 281.81 & 292.52 & 305.92 & 323.20 & 204.84 & 216.23 & 229.79 & 246.23 \\
\hline Vietnam & 162.64 & 153.11 & 141.17 & 125.78 & 132.68 & 122.54 & 110.46 & 95.82 \\
\hline Korea, Rep. & 209.01 & 222.68 & 239.79 & 261.85 & 146.65 & 161.19 & 178.51 & 199.49 \\
\hline Colombia & 173.46 & 165.36 & 155.21 & 142.13 & 139.61 & 130.99 & 120.72 & 108.28 \\
\hline Peru & 171.41 & 162.31 & 150.91 & 136.22 & 138.97 & 129.28 & 117.75 & 103.78 \\
\hline $\begin{array}{c}\text { Congo, } \\
\text { D.R. }\end{array}$ & 67.41 & 62.61 & 56.61 & 48.87 & 55.77 & 50.67 & 44.59 & 37.23 \\
\hline Kenya & 101.95 & 95.20 & 86.74 & 75.83 & 83.89 & 76.71 & 68.14 & 57.77 \\
\hline Australia & 98.88 & 144.18 & 200.91 & 274.06 & 33.61 & 81.81 & 139.23 & 208.78 \\
\hline Nepal & 89.61 & 83.34 & 75.49 & 65.37 & 74.04 & 67.37 & 59.43 & 49.80 \\
\hline $\begin{array}{l}\text { Cote } \\
\text { d'Ivoire }\end{array}$ & 122.66 & 114.88 & 105.13 & 92.55 & 100.62 & 92.33 & 82.47 & 70.51 \\
\hline Uganda & 68.19 & 63.36 & 57.32 & 49.53 & 56.39 & 51.26 & 45.14 & 37.74 \\
\hline Bolivia & 155.95 & 147.86 & 137.73 & 124.67 & 126.25 & 117.65 & 107.40 & 94.98 \\
\hline Cambodia & 108.98 & 101.56 & 92.28 & 80.30 & 89.85 & 81.96 & 72.56 & 61.18 \\
\hline Senegal & 114.40 & 107.20 & 98.19 & 86.58 & 93.78 & 86.12 & 77.00 & 65.96 \\
\hline Norway & 210.36 & 222.04 & 236.66 & 255.52 & 149.50 & 161.93 & 176.73 & 194.66 \\
\hline
\end{tabular}

\section{Conclusions}

The paper argues that equity principles should be used to reduce the complexity of international climate negotiations. Combining generally agreed principles and including economic dynamics, I develop a simple rule for burden sharing in international climate policy. The resulting allocation of carbon budgets comprises both the egalitarian and the cost distribution aspect, which both appear to be crucial for political acceptance. The calculated carbon budgets for the different countries show the absolute values 
Table 4. Average budget per capita per year (period 2008-2050 in tons)

\begin{tabular}{|c|c|c|c|c|c|c|c|c|}
\hline \multirow{2}{*}{$\begin{array}{l}\text { Country } \\
\text { name }\end{array}$} & \multicolumn{4}{|c|}{$50 \%$ probability } & \multicolumn{4}{|c|}{$33 \%$ probability } \\
\hline & $\theta=1$ & $\theta=0.8$ & $\theta=0.5$ & $\theta \rightarrow 0$ & $\theta=1$ & $\theta=0.8$ & $\theta=0.5$ & $\theta \rightarrow 0$ \\
\hline China & 5.24 & 5.11 & 4.95 & 4.74 & 4.11 & 3.97 & 3.81 & 3.61 \\
\hline India & 3.98 & 3.77 & 3.51 & 3.17 & 3.23 & 3.00 & 2.74 & 2.41 \\
\hline $\begin{array}{l}\text { United } \\
\text { States }\end{array}$ & 2.02 & 3.32 & 4.95 & 7.06 & 0.34 & 1.72 & 3.38 & 5.38 \\
\hline Indonesia & 4.28 & 4.06 & 3.79 & 3.43 & 3.46 & 3.23 & 2.95 & 2.62 \\
\hline $\begin{array}{l}\text { Russian } \\
\text { Fed. }\end{array}$ & 5.43 & 6.06 & 6.84 & 7.86 & 3.56 & 4.23 & 5.02 & 5.99 \\
\hline Brazil & 4.49 & 4.29 & 4.04 & 3.73 & 3.60 & 3.39 & 3.14 & 2.84 \\
\hline Japan & 5.45 & 5.84 & 6.32 & 6.94 & 3.80 & 4.21 & 4.69 & 5.28 \\
\hline Mexico & 4.62 & 4.57 & 4.50 & 4.41 & 3.57 & 3.51 & 3.44 & 3.36 \\
\hline Germany & 5.21 & 5.72 & 6.36 & 7.18 & 3.50 & 4.04 & 4.69 & 5.47 \\
\hline Nigeria & 3.00 & 2.81 & 2.58 & 2.29 & 2.45 & 2.26 & 2.02 & 1.74 \\
\hline Bangladesh & 2.82 & 2.63 & 2.39 & 2.08 & 2.32 & 2.12 & 1.88 & 1.59 \\
\hline France & 5.46 & 5.56 & 5.69 & 5.86 & 4.07 & 4.17 & 4.30 & 4.46 \\
\hline $\begin{array}{l}\text { United } \\
\text { Kingdom }\end{array}$ & 5.17 & 5.54 & 6.00 & 6.59 & 3.60 & 3.99 & 4.46 & 5.02 \\
\hline Thailand & 5.10 & 4.98 & 4.82 & 4.62 & 4.00 & 3.87 & 3.71 & 3.52 \\
\hline Turkey & 4.61 & 4.50 & 4.38 & 4.21 & 3.60 & 3.49 & 3.37 & 3.21 \\
\hline Ukraine & 6.71 & 6.96 & 7.28 & 7.70 & 4.88 & 5.15 & 5.47 & 5.86 \\
\hline Vietnam & 3.87 & 3.65 & 3.36 & 2.99 & 3.16 & 2.92 & 2.63 & 2.28 \\
\hline Korea, Rep. & 4.98 & 5.30 & 5.71 & 6.23 & 3.49 & 3.84 & 4.25 & 4.75 \\
\hline Colombia & 4.13 & 3.94 & 3.70 & 3.38 & 3.32 & 3.12 & 2.87 & 2.58 \\
\hline Peru & 4.08 & 3.86 & 3.59 & 3.24 & 3.31 & 3.08 & 2.80 & 2.47 \\
\hline $\begin{array}{c}\text { Congo, } \\
\text { D.R. }\end{array}$ & 1.60 & 1.49 & 1.35 & 1.16 & 1.33 & 1.21 & 1.06 & 0.89 \\
\hline Kenya & 2.43 & 2.27 & 2.07 & 1.81 & 2.00 & 1.83 & 1.62 & 1.38 \\
\hline Australia & 2.35 & 3.43 & 4.78 & 6.53 & 0.80 & 1.95 & 3.31 & 4.97 \\
\hline Nepal & 2.13 & 1.98 & 1.80 & 1.56 & 1.76 & 1.60 & 1.41 & 1.19 \\
\hline $\begin{array}{l}\text { Cote } \\
\text { d'Ivoire }\end{array}$ & 2.92 & 2.74 & 2.50 & 2.20 & 2.40 & 2.20 & 1.96 & 1.68 \\
\hline Uganda & 1.62 & 1.51 & 1.36 & 1.18 & 1.34 & 1.22 & 1.07 & 0.90 \\
\hline Bolivia & 3.71 & 3.52 & 3.28 & 2.97 & 3.01 & 2.80 & 2.56 & 2.26 \\
\hline Cambodia & 2.59 & 2.42 & 2.20 & 1.91 & 2.14 & 1.95 & 1.73 & 1.46 \\
\hline Senegal & 2.72 & 2.55 & 2.34 & 2.06 & 2.23 & 2.05 & 1.83 & 1.57 \\
\hline Norway & 5.01 & 5.29 & 5.63 & 6.08 & 3.56 & 3.86 & 4.21 & 4.63 \\
\hline
\end{tabular}

and the sensitivity of the results with respect to the assumption on historic responsibility.

One can extend the discussion to more complex combinations of the different principles and their valuation. The coming political debate might find reasons to do so. But the simplicity of burden sharing rules have their clear merits: they can provide well-defined guidelines and, particularly, help to cut negotiation cost. The present paper finds a rule that respects that the burden of emission abatement has to be shared, but includes the other basic principles like the ability to pay for climate policies in an 
equal way. The nonlinear impact of initial emissions per capita on the fairness index smooths the carbon budget differences between the countries, which guides the way towards a long-term future with an equal sharing of atmospheric resources.

It has recently been argued that principles and indicators can provide insight, but no magic formula. Hence, to be precise, we stress that there is nothing 'magic' about the proposed solution, but something potentially useful for current climate negotiations: a benchmark (and maybe even a blueprint) for a highly complicated decision-making process towards an acceptable outcome for international climate policy. What is needed is a convincing plan to reconcile the opposing views of high- and lowdeveloped countries, which has to find a balance between egalitarian and efficiency aspects of climate policies. There might be valuable alternatives to the present solution. But if an agreement is to be reached soon, the debate has now definitely to shift from all the issues which are not promising to things that may work in the end.

\section{References}

Anthoff, D. and R. Tol (2010), 'On international equity weights and national decision making on climate change', Journal of Environmental Economics and Management 60: 14-20.

Barrett, S. (2005), 'The theory of international environmental agreements', in K.G. Mäler and J.R. Vincent (eds), Handbook of Environmental Economics, Volume 3, Amsterdam: Elsevier, chapter 28.

BASIC (2011), 'Equitable access to sustainable development: contribution to the body of scientific knowledge', BASIC expert group, Beijing, Brasilia, Cape Town and Mumbai.

Blanford, G.J., R.G. Richels, and T.F. Rutherford (2008), ‘Why post-Kyoto climate policy must look East', Discussion Paper No. 08-06, Harvard Project on International Climate Agreements, Belfer Center for Science and International Affairs, Harvard Kennedy School, Cambridge, MA.

Bode, S. (2004), 'Equal emissions per capita over time-a proposal to combine responsibility and equity of rights for post-2012 GHG emission entitlement allocation', European Environment 14(5): 300-316.

Bosello, F., B. Buchner, and C. Carraro (2003), 'Equity, development, and climate change control', Journal of the European Economic Association 1(2/3): 601-611.

Bosetti, V. and J. Frankel (2009), 'Global climate policy architecture and political feasibility: specific formulas and emission targets to attain $460 \mathrm{PPM} \mathrm{CO}^{2}$ concentrations', Discussion Paper No. 09-30, Harvard Project on Climate Agreements, Belfer Center for Science and International Affairs, Harvard Kennedy School, Cambridge, MA.

Bretschger, L. and N. Suphaphiphat (2012), 'Use less, pay more: can climate policy address the unfortunate event for being poor?', Economics Working Paper Series No. 12/166, CER-ETH, Zurich.

Bretschger, L. and S. Valente (2011), 'Climate change and uneven development', Scandinavian Journal of Economics 113(4): 825-845.

Bretschger, L., R. Ramer, and F. Schwark (2011), 'Growth effects of carbon policies: applying a fully dynamic CGE model with heterogeneous capital', Resource and Energy Economics 33(4): 963-980.

Cazorla, M. and M. Toman (2000), 'International equity and climate change policy', Climate Issue Brief No. 27, Resources for the Future, Washington, DC. 
Clarke, L., J. Edmonds, V. Krey, R. Richels, S. Rose, and M. Tavoni (2009), 'International climate policy architectures: overview of the EMF 22 international scenarios', Energy Economics 31: 64-81.

Gersbach, H. and R. Winkler (2011), 'International emission permits markets with refunding', European Economic Review 55: 759-773.

Grasso, M. (2007), 'A normative ethical framework in climate change', Climatic Change 81(3): 223-246.

Johansson-Stenman, O. and J. Konow (2010), 'Fair air: distributive justice and environmental economics', Environmental and Resource Economics 46: 147-166.

Konow, J. (2003), 'Which is the fairest one of all? A positive analysis of justice theories', Journal of Economic Literature 41(4): 1188-1239.

Lange, A., C. Vogt, and A. Ziegler (2007), 'On the importance of equity in international climate policy: an empirical analysis', Energy Economics 29: 545-562.

Lange, A., A. Löschel, C. Vogt, and A. Ziegler (2010), 'On the self-interested use of equity in international climate negotiations', European Economic Review 54: 359-375.

Mattoo, A. and A. Subramanian (2010), 'Equity in climate change', Policy Research Working Paper No. 5383, World Bank, Washington, DC.

McKibbin, W.J., A. Morris, and P.J. Wilcoxen (2010), 'Comparing climate commitments: a model-based analysis of the Copenhagen accord', Discussion Paper No. 10-35, Harvard Project on International Climate Agreements, Belfer Center for Science and International Affairs, Harvard Kennedy School, Cambridge, MA.

Meinshausen, M., N. Meinshausen, W. Hare, et al. (2009), 'Greenhouse-gas emission targets for limiting global warming to $2^{\circ} \mathrm{C}^{\prime}$, Nature 458: 1158-1163.

Metz, B. (2000), 'International equity in climate change policy', Integrated Assessment 1(2): 111-126.

Odell, J.S. (2006), Negotiating Trade: Developing Countries in the WTO and NAFTA, Cambridge: Cambridge University Press.

Page, E.A. (2008), 'Distributing the burdens of climate change', Environmental Politics 17(4): 556-575.

Posner, E.A. and D.A. Weisbach (2012), 'International Paretianism: a defense', University of Chicago Institute for Law \& Economics Olin Research Paper No. 606, University of Chicago, Chicago, IL.

Rose, A., B. Stevens, J. Edmonds, and M. Wise (1998), 'International equity and differentiation in global warming policy', Environmental and Resource Economics 12: 25-51.

Schelling, T.C. (1980), The Strategy of Conflict, Cambridge, MA: Harvard University Press.

Schelling, T.C. (1995), 'Intergenerational discounting', Energy Policy 23(4/5): 395401.

Tavoni, M., S. Chakravarty, and R. Socolow (2012), 'Safe vs. fair: a formidable tradeoff in tackling climate change', Sustainability 4: 210-226.

UNFCCC (United Nations Framework Convention on Climate Change) (2011), 'Ad Hoc Working Group on the Durban Platform for Enhanced Action (ADP)', [Available at] http://unfccc.int/bodies/body/6645.php.

World Bank (2010), World Development Report 2010, Development and Climate Change, Washington, DC: World Bank.

World Bank (2012), WDI online, [Available at] http://data.worldbank.org/datacatalog/world-development-indicators. 